\title{
A tribute to Betty Tillman
}

\author{
Richard B. McKenzie
}

Published online: 13 November 2013

(C) Springer Science+Business Media New York 2013

Most academics who write for this journal (or any other) seek professional recognition, if not fame, at some level. Their fondest hope is to cast a professional shadow larger than their own personal shadow in late afternoon. They freely offer attribution, but mainly to their faculty colleagues who have worked with them. Few seek to work in the shadows of others. Still fewer seek to deflect attribution when it is well deserved. Some academics end their careers frustrated by the absence of due recognition. Most will end their lives with their largest impact on their own resumes, with limited impact on others, and with even smaller effects on their professions. The Holy Grail of the academic realm is to leave a meaningful professional mark that can be measured by publications, citations, impact on students, and personal honors widely known.

Betty Tillman lived with a far larger personal and community purpose guiding her daily work. She was dedicated to fostering the considerable scholarship of James Buchanan, helping in whatever ways she could to lift from him the drudgeries of daily academic life. Much of her work with him came at a time before the advent of computers-when papers had to be readied for publication by transcribing JMB's hand-written scrawls onto pages that passed through typewriters with, of course, carbon copies that made the transcriptions timeintensive chores. She also served as Jim's gatekeeper and travel agent (among so many other things) when his time for thought was under siege from many and his travels took him to numerous points on the globe every year. With Jim's steady and enormous flow of publications, just keeping his resume up to date must have been a nontrivial task for Betty. Keeping his easily ignited frustrations in check was never a part of her job description, but was still an unsung duty she did with grace.

Without doubt, Betty enabled Jim to extend the professional shadow he cast in major ways, and he knew it deep in his heart, although he was too private a person to allow his true respect and appreciation for Betty to surface openly and freely. Nevertheless, Jim's admiration for Betty was transparent. On those rare occasions that Jim was asked to pay

R.B. McKenzie ( $\varangle)$

Merage School of Business, University of California, Irvine, CA 92697, USA

e-mail: mckenzie@uci.edu 
tribute to Betty, he easily let his guard down on his emotional side: He choked, visibly, rightfully so. He had a connection with her that no one else had, or could have. They were a team.

But as everyone who had the pleasure of crossing Betty's path in life knows, she also cast a shadow on the profession through the power of her calm goodness, always willing to greet anyone who came through the Public Choice Center's front doors with a huge smile and a warm hug, often accompanied by a cheerful "Well, hello, darling!" As a graduate student at Virginia Tech, I remember Betty as someone who was always eager to listen and, when the frustrations of my studies piled up, to offer a form of motherly comfort and encouragement. Amidst all the solemn economics talk from everyone in the Center, she was willing to listen to my and others' efforts to find humor. She could beam with a smile and a hearty laugh that was unmistakable at some distance. I found a form of acceptance and generosity in Betty's placing me among her special "boys," as did everyone else who passed through the Center and came under professional demands that were always beyond their reach. I and others reached far further than we would have without Betty's presence.

There are people in this world who are an unrecognized powerful medium that enable others to achieve far more than they could possibly achieve individually without their unifying (and mysterious and unrecognized) force. Betty made the whole greater than the sum of its parts.

Ironically, Betty worked among academics who founded abiding theories on how individuals had precious little incentive to produce collective goods on their own. Yet there she was, quietly and without notice producing the very collective good that was being denied.

It is true that she worked her days in the relatively small group at the Center, but her collective good extended well beyond the boundaries of her university (wherever it was) into the far corners of the profession, as her "boys" worked their ways through their careers. On hearing of Betty's death, each of her "boys" has no doubt paused to reflect on the reach of her shadow.

When Jim Buchanan was awarded the Noble Prize, Betty was there-just off to the side, enjoying every minute of his recognition and never asking for any for herself. However, I am confident that a theme of the tributes provided here will be this: Betty cast one very large shadow and never asked to be recognized for the duties to which she held true, and the heartwarming good she did for so many. 